\title{
Traditional Medicines and Cancer Therapies in African Landscape
}

\author{
Adlama $\mathrm{Ly}^{1,2 *}$ \\ ${ }^{1}$ GR "Prevention and physiopathology of cancers", International Center for Cancer Treatment and Research (ICCTR), France
}

${ }^{2}$ Afrocancer, International Network for Cancer Control in Africa, Africa

Submission: March 03, 2018; Published: April 12, 2018

*Corresponding author: Adama Ly, GR" Prevention and physiopathology of cancers", International Center for Cancer Treatment and Research (ICCTR), France and Afrocancer, International Network for Cancer Control in Africa, Afrocancer, BP 60751, 75827 Paris Cedex 17, France, Email: adamaly@gmail.com

\begin{abstract}
Since from the earliest times, traditional medicines (TM) are widely used by many communities in all continents in both developed and developing countries. Nevertheless, TM are in most cases unrecognized due to the lack of evidence - based medicine validation procedures (preclinical and clinical studies). In Africa, TM are still used (sometimes misused) by patients and traditional healers for their availability and affordability. Despite these economic considerations, TM are strongly connected to the social, cultural and worship life of populations. In parallel, during the last decades, because of the stagnation or the slowdown in the new drugs discovery, they're a great and growing interest from the pharmaceutical firms in TM for bio-prospecting. In doing so, many anti-cancer molecules have already been found for instance from Madagascar periwinkle or from Pygeum africanum and many others could be discovered thanks to the potentials and biodiversity of the African nature and the richness of the African traditional knowledge. However, biopiracy remains a huge problem in the absence of intellectual property rights. In fact, the misunderstanding lies on the fact that traditional healer's aims are not only to further modern or western medicine but to preserve and improve their knowledge and to gain financial profit. Finally, defined as Alternatives Medicines (AM) or Complementary Medicines (CM) according to the world's regions and its terms of use and in contrast to the conventional or modern medicine (MM), TM could give enormous and great opportunities for cancer and non communicable diseases therapies. At present, the cancer burden in African areas is overwhelming and its control will be tough in the near future as epidemiological perspectives are so alarming. Otherwise, the usefulness of TM is fundamental in the preservation of threatens species and traditional knowledge. Consequently, a balanced approach and a mutually beneficial partnership between traditional medicine and conventional medicine must be found by local and global health politics.
\end{abstract}

Keywords: Traditional medicine; Africa; Cancer; Anti-cancer drugs; Traditional healers; Alternatives medicines; Complementary medicines; Bioprospecting; Biopiracy; Plants; Health politics

\section{Introduction}

Used since the earliest times, traditional medicines (TM) are widespread throughout the world and on all continents. The World Health Organization (WHO) estimates that 5.6 billion people, or $80 \%$ of the world's population, use traditional medicines for primary health care in Africa, Asia, Latin America and even industrialized countries like Europe where there is a growing interest in these non-standard therapies [1-4]. In Africa, the vast majority of the population, especially those living in rural areas, use traditional medicines for their health safety, from most benign to the most serious diseases, including cancer. In remote areas of large city capitals, TM are the first choice because it's the only opportunity for treatment. Other explanations for the use of TM are cultural, ethnic, religious, mystical and economic [2,5].

\section{Definitions}

\section{Traditional medicines}

According to the (WHO) traditional medicines are "the total sum of knowledge, skills and practices that are based on theories, beliefs and experiences specific to a culture and that are used to maintain healthy human beings as well as to prevent, diagnose, treat and cure physical and mental illnesses" [2].

As opposed to conventional medicines, TM are referred to as Alternative Medicines or Preventive Medicines (PM). These Alternative Medicines (AM) are considered as such when they replace or when they are given at the same time as standard medicines or complementary medicines (CM). Modern or conventional medicine is the standard type of medicine that has a scientific base. It relies mostly on fundamental experiments and clinical trials before switching to practical applications on humans. These Medicines usually have already shown a certain level of efficiency or therapeutic benefits or have already demonstrated a benefit/ risk ratio which are favorable to the patients. For WHO, «traditional medicine is used in reference to Africa, Latin America, South East Asia, and /or the Western Pacific, while the term complementary and alternative medicine is used in reference to Europe and /or North America (and 
Australia). For references, in a general sense, to all these regions, the term traditional medicine/complementary medicine (TM/ $\mathrm{CM}$ ) is used [1].

\section{Traditional healers}

The traditional healer is the person, male or female, who has social and community recognition and has practical skills often passes down from generation to generation, either orally or in writing, enabling him/her to treat a variety of diseases through the use of vegetable, animal or mineral products and/or by the application of mystical-religious knowledge. He/she is almost never a specialist of any single disease or practice. His/her field of action is physical (organic) mental and psychological. By intervening in all the events of life, he establishes a relationship of trust with the inhabitants of his region who are likely to be sick in the future. There is 1 traditional healer for 500 people, compared to 1 doctor for 40,000 people in Africa [2].

\section{Use of Traditional Medicines}

In most cases, cancer patients use both therapeutic approaches. Traditional medicines are used alone (monotherapy) or in combination with conventional medicine when available (polytherapy). The use of TM is used as soon as the disease is reported and cancer treatments are administered throughout.

In case of therapeutic failure, TM act as palliative care and accompany patients with terminal illness until the end and beyond. TM are first-line treatment as soon as a disease is developed and it may be the only possibility of care in certain areas suffering from poor medical services. This type of behavior from cancer patients and the lack of a good medical system are very typical in African populations. This is the explanation of the delay in going to the hospital or to other health facilities. For cancer therapies, this represents both a delay in diagnosis and in medical care. Not going to the hospital in due time has many consequences such as a high rate of death, a high level of pain and suffering because of the progression of the disease, a higher cost for treatment and a significant loss in their chance for recovery.

Indeed, in African countries, the fight against cancer remains difficult because of the small number of specialists, the lack of technical equipment and the centralization of large health facilities in the country's own capitals. Insufficient supply of therapeutic surgery, chemotherapy and radiotherapy and the unaffordable costs of medicines and medical care make the patient's therapeutic program complicated [5-7]. At the same time, traditional therapists respond to the health needs of the majority of the population and take care of the poor by displaying affordable prices and providing immediately available health products [5].

\section{Products of Complementary Medicines}

Traditional therapeutic practices in Africa, despite their regional multiplicity and diversity, can be grouped under two types: medicinal herbal therapies (herbal therapies) and therapies by religious and/ or mystical practices.

\section{Therapy with medicinal plants}

Traditional therapy (phytotherapy) is a multi-centuries-long activity in Africa that has been maintained for generations and transmitted within the family and the ethnic group. The plants used often come from immediate and natural environment of the populations. The selection of the plant type and the associated therapeutic activity has been carried out through empirical experiments and observations over the ages. Preparations derived from medicinal plants by extraction, infusion or marination is delivered by traditional healers of this ancestral knowledge and are generally consumed orally. The limits of this traditional medicine are the lack of precision of the diagnosis and the dosage. Indeed, the active principles contained in the plants vary in quantity and quality according to the time of harvest, the technique of conservation and the part of the plant used. These traditional medicines have attracted a lot of interest from scientists and biomedical researches. Medicinal plants such as the common Black Jack (Bidens pilosa L.), originated in South America and growing in Cameroon and Madagascar, The African Potato (Hypoxis hemerocallida) from South Africa, Zimbabwe and Mozambique are known to treat adenoma and prostate cancer (Figure $1 \& 2$ ).

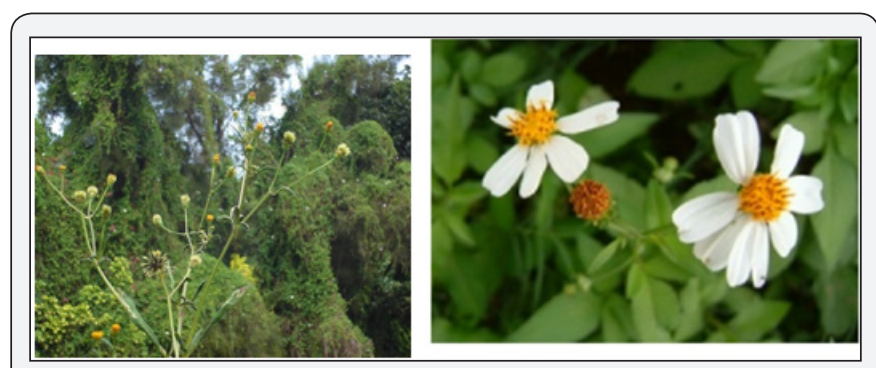

Figure 1: Bidens pilosa.

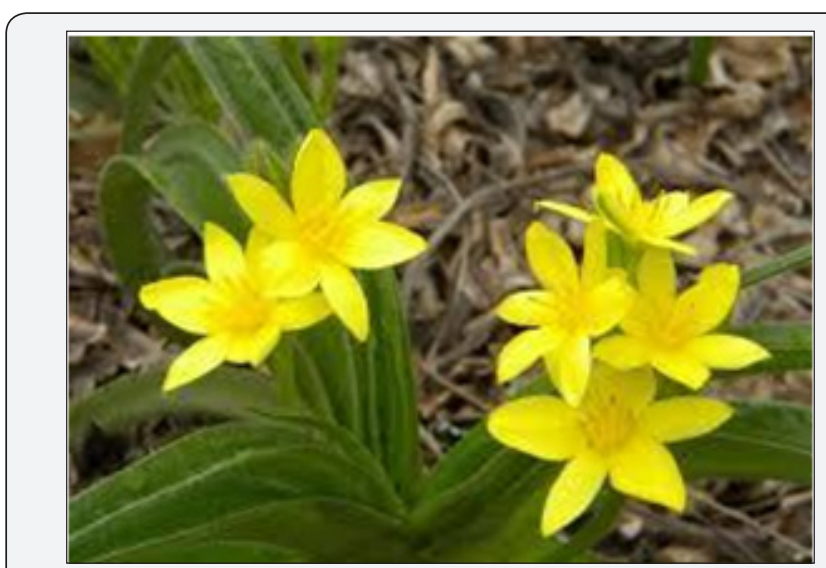

Figure 2: Hypoxis hemerocallidea.

Similarly, the bark of Prunus Africana, the African plum (called Pygeum africanum or red stinkwook), is used by traditional healers in the treatment of genitourinary disorders, benign hypertrophy prostate cancer and prostate cancer. This plant is among endangered species. In Kenya, the government has prohibited its export for its protection [8] (Figure 3). 

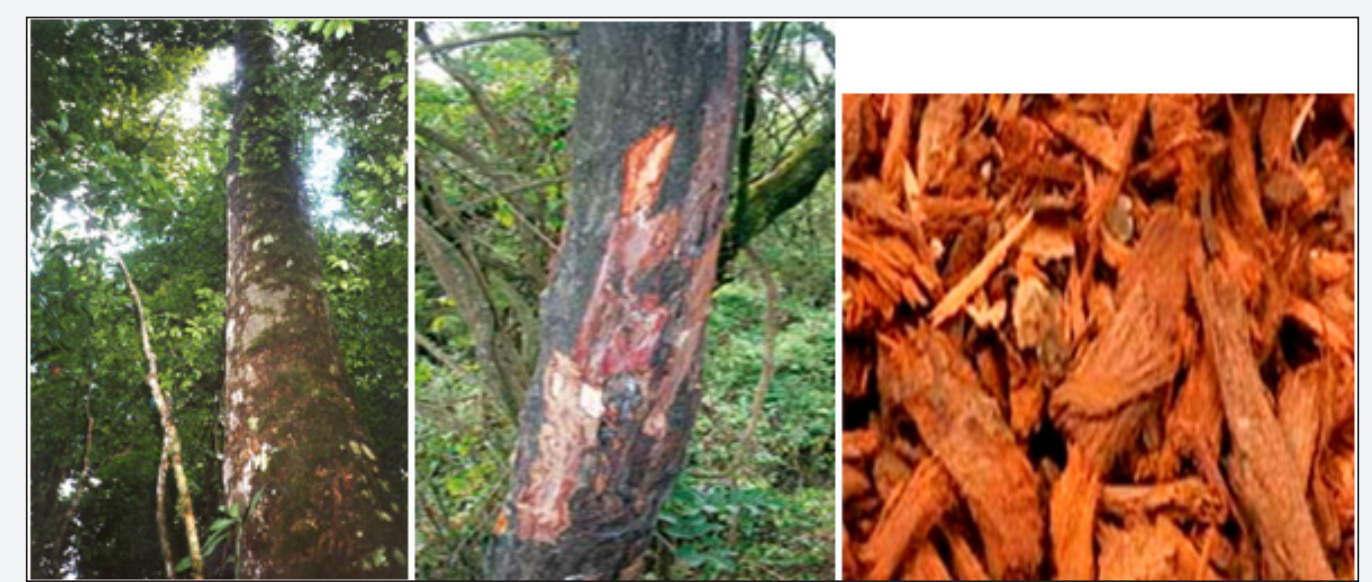

Figure 3 : Pygeum africanum.

Numerous biomedical plants such as the autumn colchicum (Colchicum autumnale L.) and the May-Apple (Podophyllum peltatum) and crotalaria sessiliflora L. are used in ethnomedicines for their anti-cancer activities. From these ethnobotanical data, the anti-tumor pharmacological properties of these plants were tested. A link has been found between the use of these plants by traditional practitioners and their therapeutic indications in conventional medicine. Indeed, the Colchicum autumn (Colchicum autumnale L.) gave colchicine. From Podophyllum peltatum are synthesized etoposide and teniposide. Crotalaria sessiliflora $L$. allows the manufacture of monocrotaline. These products are widely used for their anticancer effects in chemotherapy. In the same way, the systematic screening of medicinal plants allowed the discovery of Camptothecin from the plant Camptotheca acuminita (tree of life) and Paclitaxel (Taxol) from plant Taxus brevifolia called Yew of the west.

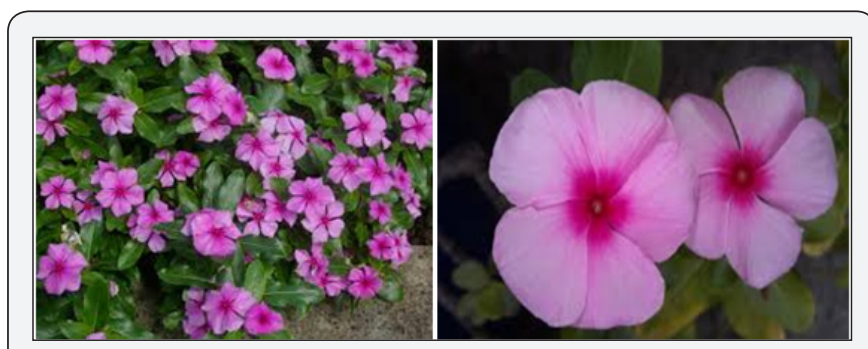

Figure 4 : Periwinkle of Madagascar.

As for vinblastine and vincristine, they are derived from the plant Catharantus roseus better known as Periwinkle of Madagascar by the same process. Today, Taxol, vinblastine and vincristine are important components of the therapeutic arsenal against cancer. However, traditional practitioners can use these plants for treatments other than those of cancers. This shows differences in the clinical practices and multiple therapeutic possibilities of medicinal plants [9,10] (Figure 4).

\section{Religious and mystical practices in anti-cancer therapies}

Besides medicinal plant, religious practices and/or mystics are among the therapeutic means of the African population to recover, to remove the evil from which they suffer and to restore a broken physical harmony. Thus, many patients with cancer resort to rituals, usually in association with medicinal plants and conventional medicine when possible, such as exorcism, offering (sacrifices), fumigation, prayers, invocations, reading sacred texts of the Koran or the Bible, visits to places of worship, use of holy water (baths and drinks).

\section{Economic, Environmental and Public Health Issues of MT}

The global market for traditional medicines has been steadily growing for several years and is valued at US $\$ 60$ billion by WHO. Strong links of interest exist between traditional medicine and conventional medicines. One-quarter (25\%) of current medicines come from the traditional pharmacopoeia $[1,2,5,11]$. Ethnobotany and ethnopharmacology specialists work with traditional healers to select plants with strong curative potential. Bio-prospecting, if useful and desired, sometimes poses problems of patents and intellectual property almost always in disfavour of traditional healers. Consequently, national and international laws must been acted to regulate this type of prospecting to lead to mutually beneficial relationships and to avoid biopiracy. In most African countries, this task of protecting cultural heritage, traditional knowledge and medicinal plants remains to be done $[11,12]$. Moreover, overexploitation of certain plant species threatens them with extinction and impoverishes biodiversity, which is made critical by forest fires or bush fires, excessive deforestation and unsustainable management of the environment. However, an unsuspected number of potentially anti-cancer molecules could originate from African ecosystems if a large-scale pharmaceutical prospecting activity is organized and regulated $[2,11,12]$.

\section{Traditional Medicines/ Improved Traditional Medicines (ITM)}

For these reasons, the WHO says in its recommendations since 1986 that "member countries should involve traditional healers in community health care, encourage research on 
commonly used medicinal plants and expand trade with other countries in the sectors of traditional medicine". Since then, WHO, through various strategies and proposals from 2002 to 2005 and from 2014 to 2023 , has been attempting to turn traditional medicines into improved traditional medicine (ITM) with universal definitions and rules. These strategies attempt to formalize, identify and codify the products and practices of nonconventional therapies to integrate them into national health systems [1-3].

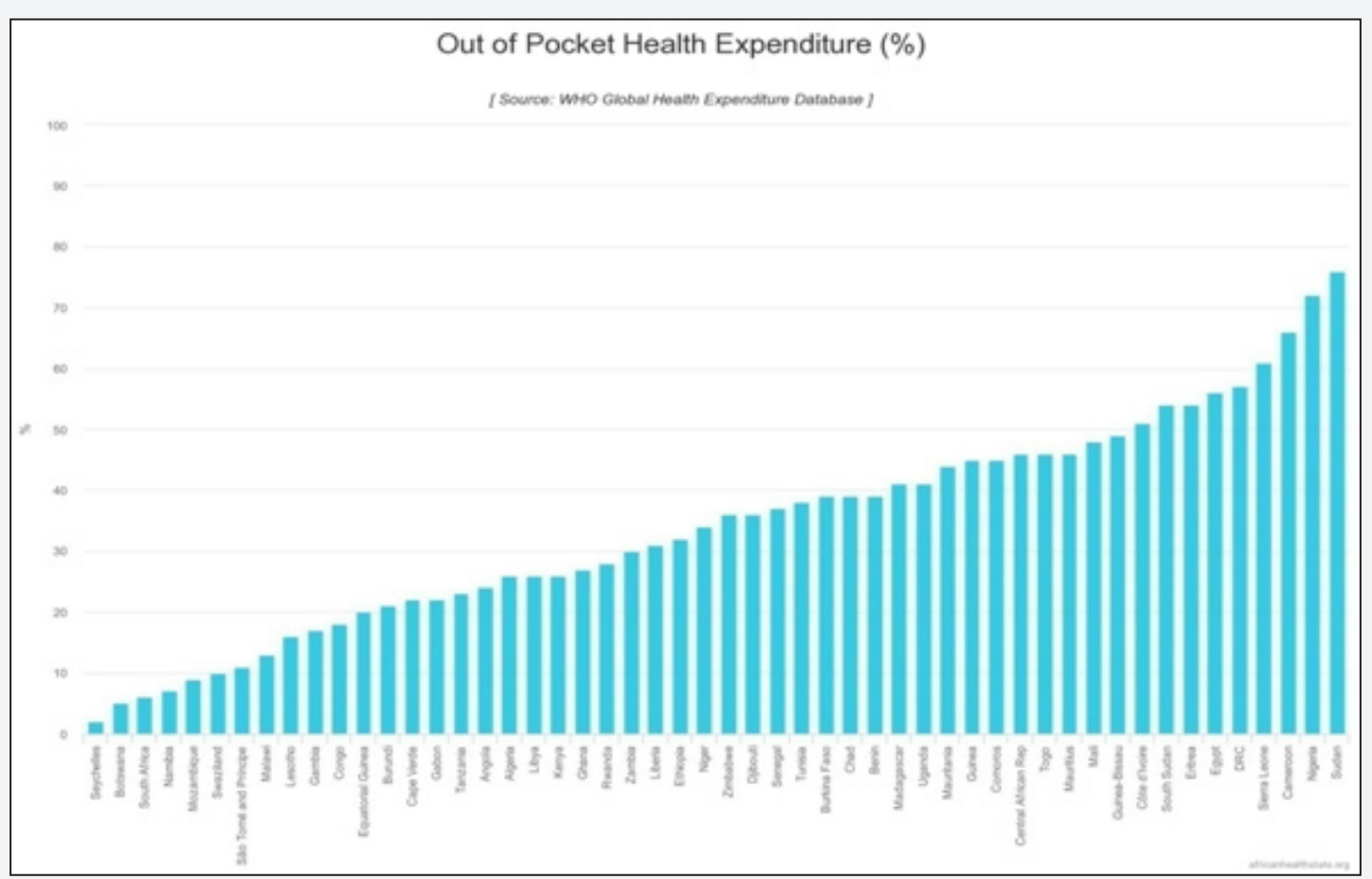

Figure 5 : Out of pocket health expenditure (\%).

(http://www.africanhealthstats.org/cms/?pagename=indicator\&indicator=HF5)

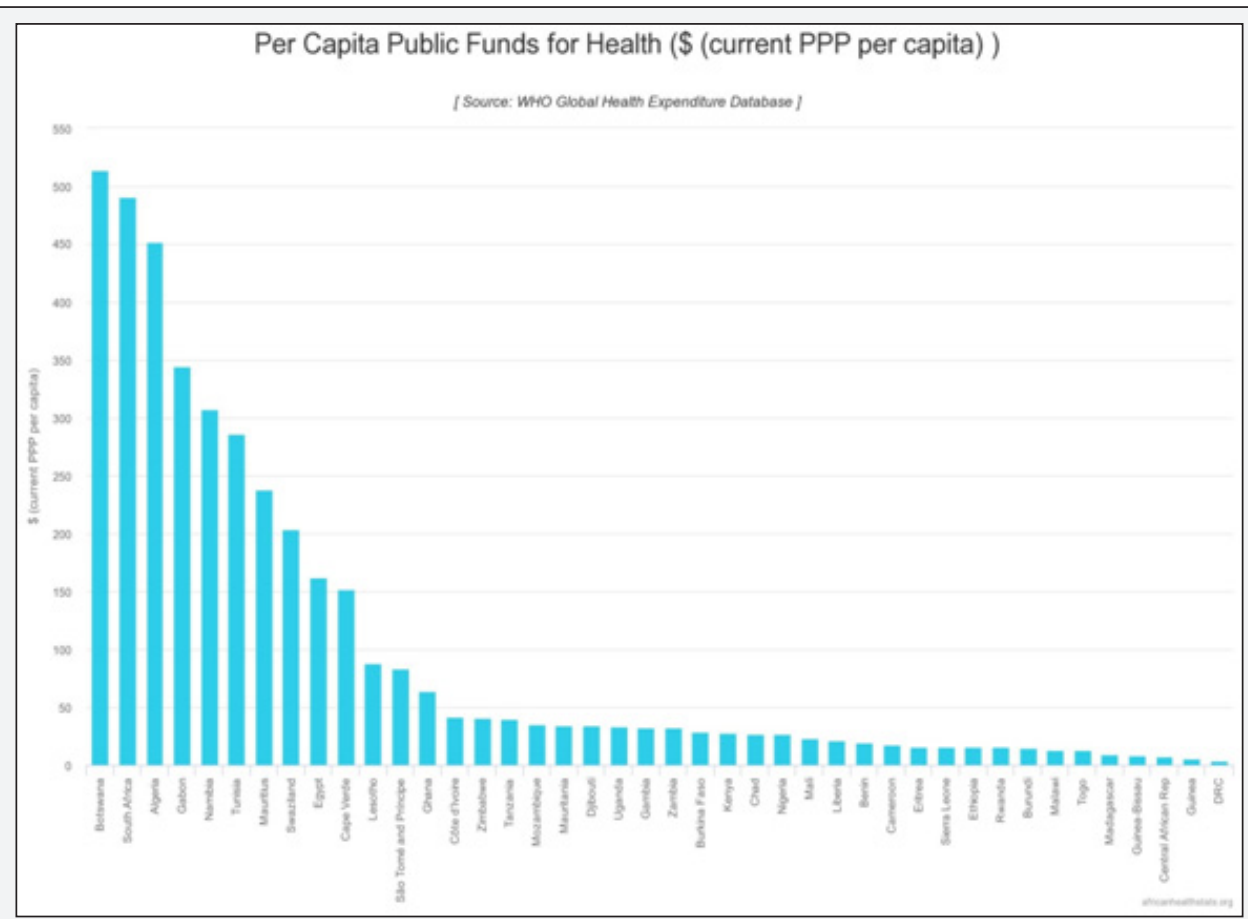

Figure 6 : Per capita public funds for health.

(http://www.africanhealthstats.org/cms/?pagename=indicator\&indicator=HF4) 
Anyhow, in many African countries, several problems must be solved before an official recognition of traditional medicines and before they become mainstream: drug effectiveness and safety, registry of traditional healers, renewable of natural resources, lack of delivery infrastructure, intellectual property rights and biopiracy [13-15] (Figure 5-7).

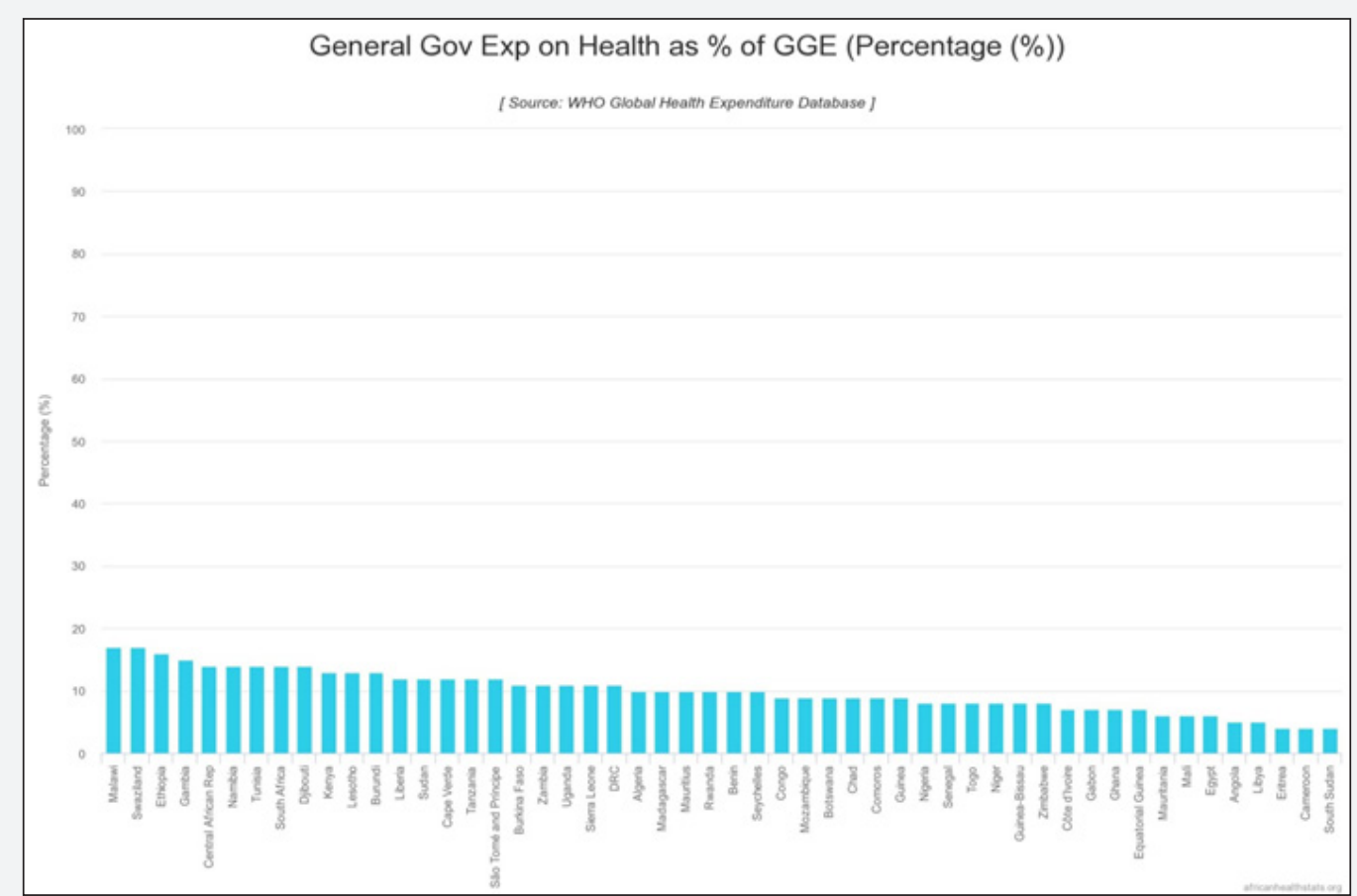

Figure 7 : General Gov exp on health as \% of GGE.

(http://www.africanhealthstats.org/cms/?pagename=indicator\&indicator=HF3)

\section{Conclusion}

We have to remember that cancer is responsible for $13 \%$ of global mortality, i.e. 8.8 million deaths of which more than 590,000 are recorded in Africa. This rate of occurrence is constantly increasing and there is an estimated of 847,000 new cases by the International Agency of the research on cancer [16]. The economic cost of cancer is estimated at 1,160 billion US dollars worldwide in 2010 and about 126 billion Euros to the 27 countries of the European Union (EU) in 2009 while in Africa it was 849 million dollars [16,17]. The responses to the cancer burden in Africa are socio-political, scientific, medical and economic. These answers are mainly local and societal and they imply a reduction of health inequalities and more efficient health system $[6,7,18]$.

To achieve these public health goals in the context of developing countries, as are the vast majority of African countries, traditional medicines have a key role to play. In any case, these health challenges require, secondly, a strengthening of the skills and human and technical capacities. That must be facilitated and supported in a sustainable way by more efficient exchanges between African countries in the sub-regions and through the whole continent and by more dynamic and effective international cooperation [19-22].

Overall, for fruitful perspectives, we think that the commitment of politics and international health institutions is of para- mount importance. We hope that high level meetings as the Global Conference on Non communicable diseases (NCDs) organized by the World Health Organization (WHO) in Montevideo (Uruguay) entitled "Enhancing policy coherence between different spheres of policy making that have a bearing on attaining SDG target 3.4 on NCDs by 2030" will contribute to "reduce by one third premature mortality from NCDs through prevention and treatment" and will help to regulate and promote the use of traditional medicines in developing countries [23].

\section{Acknowledgment}

The author would like to thank Marie Christiane Bontemps (Afrocancer, International network for cancer control, Paris, France), Pr. Jerzy Trojan (Laboratory of Gene Therapy, Faculty of Medicine, Cartagena's University, Cartagena de Indias, Colombia and Faculty of Medicine, La Sabana University, Chia, Autopista Norte de Bogota, Colombia), The French league against cancer (La Ligue Nationale Contre le Cancer, Paris, France), Alliance of African and Mediterranean French speaking Leagues for cancer control (L'Alliance des Ligues francophone Africaines et Méditerranéennes contre le cancer (ALIAM, Paris, France), Professor Pierre Duez, Department of Pharmacognosy, Pharmacology, Nutrition, University of Mons (Belgium) and Professor Vanessa Steenkamp, Department of Pharmacology, University of Pretoria (South Africa) for their assistance and useful suggestions. 


\section{References}

1. WHO (2002) Traditional medicine strategy for 2002-2005. World Health Organization, Geneva, Switzerland, p. 70.

2. WHO (2014) Traditional medicine strategy for 2014-2023. World Health Organization, Geneva, Switzerland, p. 76.

3. World Health Organization (2001) Legal status of traditional medicine and complementary/alternative medicine: a worldwide review. World Health, Geneva, Switzerland, p. 200.

4. Gale NK, McHale JV (2015) Routledge handbook of complementary and alternative medicine, perspectives from social science and law. $\left(1^{\text {st }}\right.$ edn), Routledge publishers, Abingdon, UK, p. 410.

5. Ly A, Khayat D (2006) About cancer in Africa: from epidemiology to biomedical applications and perspectives. National Cancer Institute, Boulogne Billancourt, Paris, France.

6. Livingston J (2012) Improvising medicine, an African oncology ward in an emergency cancer epidemic. Duke University Press, p. 248.

7. Ly A (2016) Global health, cancer challenges and control in African settings. Cancer Therapy \& Oncol Int J 2(3): 1-4.

8. Chege K (2004) Kenya to develop traditional medicine action plan. Sci Dev Net.

9. Steenkamp V (2006) Prostate cancer and phytomedicines. In: Ly A, Khayat D (Eds.), About cancer in Africa: from epidemiology to biomedical applications and perspectives, Published by the National Cancer Institute of France (INCa), Boulogne Billancourt, France, pp. 611-616.

10. Duez P (2006) Ethnopharmacology, traditional medicines, cancer therapies in Africa. In: Ly A, Khayat D (Eds.), About cancer in Africa: from epidemiology to biomedical applications and perspectives, national cancer institute editions, Boulogne Billancourt, France, pp. 639-634.

11. Chibale K, Davies-Coleman M, Masimirembwa C (2012) Drug discovery in Africa: effects of genomics, natural products, traditional medicines, insights into medicinal chemistry, and technology platforms in pursuit of new drugs. Springer-Verlag; Berlin Heidelberg, Germany.
12. Ly A (2015) Cancer and alternative therapies in Africa. Herbals and natural remedies, Herbals Summit 2015, October 26-27, Chicago, USA,

13. Kokwaro J0 (2009) Medicinal plants of East Africa. ( $3^{\text {rd }}$ edn), Kenya Literature Bureau, Nairobi, Kenya, p. 401.

14. Awodele O, Amagon KI, Wannang NN, Aguiyi JC (2014) Traditional medicine policy and regulation in Nigeria: an index of herbal medicine safety. Curr Drug Saf 9(1): 16-22.

15. Dickson D (2002) Traditional knowledge and modern science. Sci Dev Net.

16. Stewart BW, Wild CP (2014) World cancer report 2014. International Agency for Research on Cancer, Lyon, France.

17. The Economist (2009) Breakaway: the global burden of cancer -challenges and opportunities. Economist Intelligence Unit Limited, London, UK.

18. Fullman N, Barber RM, Abajobir AA, Abate KH, Abbafati C, et al. (2017) Measuring progress and projecting attainment on the basis of past trends of the health-related sustainable development goals in 188 countries: an analysis from the global burden of disease study 2016. Lancet 390(10100): 1423-1459.

19. McCarthy M, Maher D, Ly A, Ndip A (2010) Developing the agenda for European Union collaboration on non-communicable diseases research in Sub-Saharan Africa. Health Res Policy Syst 8: 13.

20. Sylla BS, Wild CP (2012) Cancer burden in Africa in 2030: Invest today and save tomorrow. J Afr Cancer 4: 1-2.

21. The Lancet Global health (2016) Financing for health: where there's a will... Lancet Glob Health 4(10): e663.

22. World Health Organization (WHO) (2017) World health statistics 2017: monitoring health for the SDGs, Sustainable Development Goals, World Health Organization, Geneva, Switzerland.

23. WHO (2017) Montevideo roadmap 2018-2030 on NCDs as a sustainable development priority. WHO Global Conference on Non communicable Diseases pursuing policy coherence to achieve SDG target 3.4 on NCDs. Montevideo, Uruguay.

\section{Your next submission with Juniper Publishers will reach you the below assets}

